\title{
小麦多子房和单子房性状的差异蛋白质组学研究
}

王志军 马守才* 毕晓静 史秀秀 李清峰 韩 芳 元佳佳
王书平 张改生 牛 娜

西北农林科技大学国家杨凌农业生物技术育种中心 / 国家小麦改良中心杨凌分中心 / 小麦育种教育部工程研究中心 / 陕西省作物 杂种优势研究与利用重点实验室, 陕西杨凌 712100

摘 要: 以小麦单子房品系 77(2)及其多子房近等基因系 Mu77(2)为材料, 采用 TCA-丙酮法提取穗分化至四分体时期 的幼穗总蛋白, 并通过 IEF/SDS-PAGE 双向凝胶电泳分离, 获得了分辨率和重复性较好的蛋白质组差异图谱。在等电 点 4 7、分子量 14.4 97.4 $\mathrm{kD}$ 之间发现约 450 个肉眼可辨的蛋白点, 其中上调 2 倍以上且达到 $99 \%$ 统计学显著水平 的差异表达蛋白点 30 个。对 6 个特异性差异蛋白点作二级质谱(LC-MS/MS)分析, 结果表明它们是富含甘氨酸 RNA 结合蛋白(S1)、SGT1-1(S2)、HMG-I/Y(S3)、谷胱甘肽转移酶(S4)、果糖 1,6-二磷酸醛缩酶(S5)和未知蛋白(S6)。这些 蛋白质对 DNA 转录、蛋白质翻译、能量转换及代谢、抗逆防卫等生理生化过程起调控作用, 可能与小麦多子房性状的形 成有关。

关键词: 小麦; 多子房; 二级质谱; 双向电泳

\section{Differential Proteomics on Multi-Ovary and Mono-Ovary Trait of Wheat}

WANG Zhi-Jun, MA Shou-Cai ${ }^{*}$, BI Xiao-Jing, SHI Xiu-Xiu, LI Qing-Feng, HAN Fang, QI Jia-Jia, WANG Shu-Ping, ZHANG Gai-Sheng, and NIU Na

Northwest A\&F University, National Yangling Agricultural Biotechnology \& Breeding Center / Yangling Branch of State Wheat Improvement Center / Wheat Breeding Engineering Research Center, Ministry of Education / Key Laboratory of Crop Heterosis of Shaanxi Province, Yangling 712100 , China

Abstract: Muliti-ovary is a favorable trait that might be a solution for increasing the yield of hybrid seed in wheat. In this study, the differential proteins of panicles at tetrad stage were detected between the mono-ovary line 77(2) and its near-isogenic multi-ovary line Mu77(2) using SDS-PAGE method. Approximately 450 protein spots were observed in the 2-DE gels within the area of $\mathrm{pH} 4-7$ and molecular weight $14.4-97.4 \mathrm{kD}$, of which 30 were identified as differential protein spots with at least double expression levels and $99 \%$ statisticalty significant difference. Six specific protein spots with differential expressions were then analyzed using LC-MS/MS method. The result showed that they are glycine-rich RNA-binding protein (S1), SGT1-1 (S2), HMG-I/Y protein (S3), glutathione transferase (S4), fructose-bisphosphate aldolase (S5), and unnamed protein (S6). These proteins are involved in the regulation of DNA transcription, protein translation, energy metabolism, signal transduction, plants defense, and other resistance function, and might be related to the formation of multi-ovary in wheat.

Keywords: Wheat; Multi-ovary trait; LC-MS/MS; Two-dimensional electrophoresis

杂种优势利用是目前提高作物产量和改良作物品质 的重要途径之一, 已在玉米、水稻、油菜等重要农作物中 大规模应用。杂交小麦虽然经过几十年的研究, 取得了巨 大的进步，但目前仍未走向生产应用，其中一个重要制约 因素就是小麦种子繁殖系数低, 制种成本偏高。小麦多子
房种质是一种新型材料, 表现为小花内有 $2 \sim 3$ 枚雌莎和 3 枚雄莎, 结实较稳定, 具有明显的多粒性状 ${ }^{[1]}$ 。多子房性 状可有效提高小麦的繁殖系数, 在杂交小麦制种中有望 解决种子产量低、成本高、效益低的主要问题, 有可能成 为当前杂交小麦研究与应用的突破点, 对促进杂交小麦

本研究由国家高技术研究发展计划(863计划)项目(2009AA101102), 陕西省自然科学基金(2012JM3003)和西北农林科技大学 2009年唐 仲英育种基金资助。

“通讯作者(Corresponding author): 马守才, E-mail: mashoucai@sohu.com, Tel: 13991218803

第一作者联系方式: E-mail: bynerswzj@163.com, Tel: 13779701824

Received(收稿日期): 2012-02-16; Accepted(接受日期): 2012-06-06; Published online(网络出版日期): 2012-07-03.

URL: http://www.cnki.net/kcms/detail/11.1809.S.20120703.0858.201209.0_012.html 
大面积推广具有实践意义 ${ }^{[2]}$ 。

近 30 年来, 已有学者先后报道了多子房小麦花器官 的发育过程 ${ }^{[3]}$ 、种子萌发过程中的生理生化 ${ }^{[4]}$ 、分子标记 ${ }^{[5]}$ 以 及多子房性状外显率表达 ${ }^{[6]}$ 。此外, 沈光华等 ${ }^{[7]}$ 确定了控 制多子房性状的基因 $m 1$ 和 $m 2$ 分别位于染色体 $5 \mathrm{D}$ 和 $6 \mathrm{~B}$ 的短臂上; 武军等 ${ }^{[8]}$ 发现在三粒小麦细胞质存在的前提 下, 其多子房性状由 1 对显性核基因控制; 马守才等 ${ }^{[9]}$ 研 究表明, 小麦多子房性状受显、隐性 2 种类型基因控制, 这 2 种基因均位于 $6 \mathrm{~B}$ 染色体。可见多子房性状的遗传比 较复杂。 $\mathrm{Li}$ 等 ${ }^{[10]}$ 首次以 $\mathrm{SSH}$ (suppression subtractive hybridization, SSH)技术分别构建了多子房和单子房相关基 因特异表达的抑制消减杂交 $\mathrm{cDNA}$ 文库, 通过对 2 个 cDNA 文库的克隆测序、EST 序列比对分析和功能分类, 表明多子房性状文库中序列涉及的功能以蛋白合成、转录 和生长发育相关蛋白为主。

蛋白质是基因表达的产物, 是生物功能的主要执行 者和最终体现者, 利用蛋白质组学分析可以检测生命活 动变化过程中蛋白质表达量及翻译后修饰等变化, 从而 阐明生物功能产生的机制 ${ }^{[11]}$ 。本研究利用双向凝胶电泳 技术分离小麦单子房性状与多子房性状的 2 个近等基因系 四分体时期的幼穗总蛋白, 构建了两者的差异表达蛋白 谱, 对特异表达的蛋白点进行二级质谱鉴定(LC-MS/MS) 和功能分析, 并根据被鉴定差异蛋白的功能进一步分析 小麦多子房性状形成过程及一些相关基因可能的作用方 式, 旨在从蛋白质水平上揭示多子房性状形成的生物学 机制。

\section{1 材料与方法}

\section{1 植物材料}

以遗传稳定的多子房小麦“多 II” 为供体亲本、单 子房小麦 77(2)为轮回亲本, 以矮败雄性不育小麦为杂交 工具材料, 先将矮败小麦(母本)与多 II(父本)杂交, 选择 多子房不育且农艺性状与 77(2)相近的 $F_{1}$ 植株再与 77(2) 回交, 以 77(2)为轮回亲本连续回交 5 代、自交 3 代, 获得 稳定遗传的近等基因系 $\left(\mathrm{BC}_{5} \mathrm{~F}_{3}\right) \mathrm{Mu} 77(2)$ 和 77(2), 分别具 有多子房性状和单子房性状。

2010 年 10 月 7 日将 Mu77(2)和 77(2)分别种植于西 北农林科技大学实验农场的 3 个实验点, 次年 4 月上旬当 小麦幼穗发育至四分体时期时取样。选择生长旺盛、外部 形态均匀一致的材料, 于冰上剥取小麦幼穗, 经液氮速冻 后, 存于 $-80^{\circ} \mathrm{C}$ 备用。

\section{2 实验仪器及试剂}

PROTEAN IEF Cell 等电聚焦系统、PROTEAN II xi Cell 垂直电泳系统、PDQuest 8.0.1 凝胶图像分析软件均为 美国 Bio-Rad 公司产品, UMAX-Power Look 2100XL 光密 度扫描仪为台湾力捷公司产品。 $\mathrm{pH} 4 \sim 7$ 的线性 IPG 胶条 (长 $17 \mathrm{~cm}$ )、两性电解质 $(\mathrm{pH} 4 \sim 6, \mathrm{pH}$ 5 7)、低熔点琼脂糖、 矿物油均为美国 Bio-Rad 公司产品。牛血清白蛋白(BSA)、
苯甲基磺酰氟(PMSF)、 $\beta$-䟽基乙醇( $\beta$-met-captoethano1)、 二甲氨基丙磺酸(chaps)、甘氨酸、三氨基甲烷(Tris)、十 二烷基硫酸纳(SDS)、丙烯酰胺(acrlamide)、甲叉双丙烯 酰胺(bis-acrlamide)、四甲基乙二胺(TEMED)、过硫酸胺 (AP)、碘乙酰胺均为 Sigma 产品, 尿素(urea)、二硫代苏 糖醇(DTT)为 Amresco 产品, 三氯乙酸、丙酮、磷酸和甘 油等试剂国产分析纯。

\section{3 蛋白质的制备和定量}

参照陈薇红等 ${ }^{[12]}$ 的方法, 稍做改动, 提取幼穗总蛋 白质, 将样品加液氮及适量 PVP (10\%)迅速研磨成粉末; 用 $-20^{\circ} \mathrm{C}$ 预冷 TCA-丙酮蛋白提取液 $(10 \% \mathrm{TCA} 、 0.07 \% \beta$ 颈基乙醇、 $1 \mathrm{mmoL} \mathrm{L}{ }^{-1} \mathrm{PMSF}$ )沉淀蛋白质, 置 $-20^{\circ} \mathrm{C}$ 沉淀 过夜, 其间振荡多次; $4^{\circ} \mathrm{C}, 25000 \times \mathrm{g}$ 离心 $30 \mathrm{~min}$, 弃上清 液, 将沉淀悬浮于 $-20^{\circ} \mathrm{C}$ 预冷的丙酮溶液(含 $0.07 \% \beta$-䟽基 乙醇, $\left.1 \mathrm{mmoL} \mathrm{L}{ }^{-1} \mathrm{PMSF}\right)$ 中, $-20^{\circ} \mathrm{C}$ 沉淀 $1 \mathrm{~h} ; 4^{\circ} \mathrm{C}, 25000 \times g$ 离心 $30 \mathrm{~min}$, 重复洗涤沉淀 4 5 次, 直至蛋白质沉淀物为 纯白色, 最后真空冷冻干燥成干粉, $-80^{\circ} \mathrm{C}$ 保存备用。或将 蛋白质干粉与裂解液 $\left[9 \mathrm{~mol} \mathrm{~L}^{-1}\right.$ 尿素 $+4 \%$ CHAPS +65 $\mathrm{mmol} \mathrm{L}^{-1} \mathrm{DTT}+0.4 \% \mathrm{IPG}$ 缓冲液( $\mathrm{pH} 4 \sim 6$ 和 $\mathrm{pH}$ 5 7)] 充分 涡旋混匀, 呈糊状。 $29^{\circ} \mathrm{C}$ 水浴 $30 \mathrm{~min}$, 振荡充分混匀后液 氮冷却, 重复此过程 2 次; 然后 $20^{\circ} \mathrm{C} 、 25000 \times g$ 离心 $30 \mathrm{~min}$, 吸取上清液备用, 按 Bradford ${ }^{[13]}$ 的方法测定蛋白浓度。

\section{4 双向电泳}

幼穗总蛋白质提取物 $(1000 \mu \mathrm{g})$ 与水化液 $\left[9 \mathrm{~mol} \mathrm{~L}^{-1}\right.$ 尿素 $+4 \%$ CHAPS $+65 \mathrm{mmol} \mathrm{L}^{-1} \mathrm{DTT}+0.2 \%$ IPG 缓冲液 $(\mathrm{pH}$ $4 \sim 6$ 和 $\mathrm{pH}$ 5 7)]共 $400 \mu \mathrm{L}$ 充分混合, 沿 PROTA1N IEF Cell 型电泳仪(Bio-Rad)聚焦槽内连续加入, 将 $17 \mathrm{~cm} \mathrm{IPG}$ 胶条胶面朝下覆盖在样品上, $20^{\circ} \mathrm{C}$ 条件下被动吸收 $1 \mathrm{~h}$, 主动水化 $14 \mathrm{~h}$, 参见叶景秀等 ${ }^{[14]}$ 的方法进行第 1 向等电聚 焦电泳; 之后, 迅速取出带样品的 IPG 胶条, 平衡 2 次, 摇床上轻摇, 各平衡 $15 \mathrm{~min}^{\circ}$ 平衡液 I 的主要成分是平衡 缓冲母液[含 $6.0 \mathrm{~mol} \mathrm{~L}^{-1}$ 尿素、 $2 \% \mathrm{SDS} 、 0.375 \mathrm{~mol} \mathrm{~L}^{-1}$ Tris- $\mathrm{HCl}(\mathrm{pH} 8.8$ ) 和 $20 \%$ 甘油] $+2 \%$ DTT (现加); 平衡液 II 的主要成分是平衡缓冲母液 $+2.5 \%$ 碘乙酰胺 (现加)。将平 衡后的 IPG 胶条移至 $13 \%$ 均匀分离胶上端, $0.5 \%$ 低熔点琼 脂糖凝胶固定胶条, 进行第 2 向电泳, 电泳结束后, 固定 (40\%甲醇 $+10 \%$ 冰乙酸 $+50 \%$ 纯水) $90 \mathrm{~min}$, 洗涤 4 次, 每 次置摇床上轻摇 $15 \mathrm{~min}$ 。最后用考马斯亮蓝 $\mathrm{G}-250$ 染色, 纯水脱色 $3 \mathrm{~h}$ 。参照汪静等 ${ }^{[15]}$ 描述的方法配制染色液。

\section{5 凝胶图像分析}

采用 UMAX Power Look 2100XL 扫描仪对凝胶进行 图像扫描, 分辨率设定为 $600 \mathrm{dpi}$, PDQuest $2 \mathrm{DE}$ 分析软件 对图像进行分析, 定义蛋白质点的大小、强弱, 斑点检测 和统计蛋白质点数目, 计算蛋白质点的分子量和等电点, 进行斑点配比, 同时对图像进行强度校正、背景消减等。

1.6 差异蛋白质的质谱鉴定

首先将样品进行胶内酶解、洗脱, 得到肽段混合物, 然后采用 LTQ-Otbitrap-Velos 质谱仪对可重复出现的 6 个 
差异蛋白进行 LC-MS/MS 鉴定。先将蛋白质数据库中的 蛋白序列进行理论酶切、碎裂, 从而构建理论谱, 然后通过 Mascot 2.3.02 软件基于串联质谱数据(二级质谱的碎片离子 信息)搜索数据库 NCBInr (http://www.ncbi.nlm.nih.gov/ Taxonomy), 根据特定的打分算法, 对实验质谱数据和理 论谱进行质量上的匹配和打分, 并对搜索结果作一些过 滤和质量控制, 再通过统计模型, 对实验肽段与数据库蛋 白理论肽段的匹配进行可信度评估, 最后从鉴定肽段中 得到鉴定蛋白, 选择得分最高的蛋白质作为鉴定结果。

\section{2 结果与分析}

\section{1 近等基因系 Mu77(2)和 77(2)的差异蛋白}

PDQuest 软件对图像的分析结果表明, 重复图谱之 间相互匹配率达 90\%。多子房小麦样品(图 1-A)和单子房 小麦样品(图 1-B)在分子量 14.4 97.4 $\mathrm{kD}$ 和 $\mathrm{pH}$ 4 7 范围内 分别存在肉眼可辨的蛋白点 464 个和 448 个, 蛋白质点主 要分布在 $\mathrm{pH} 5$ 7 范围内。上调达 2 倍或 2 倍以上并且有 99\%统计学显著性的差异点有 30 个, 被认为是差异蛋白 点, 而其他表达量相差不足 2 倍的蛋白点视为系统误差。 图 1 中标注了表达量相差较高的蛋白点, 其中点 S1 S6 为 特异性差异, 是本研究的关注重点, 图 2 是其局部放大和 三维模式图; 此外, 还有 24 个蛋白点(1 24)在表达量上有 差异, 在多子房图谱中呈上调表达的有 14个点。特异差异 点中, S2、S3 和 S5 在多子房系 Mu77(2)中表达, 而 S1、 S4 和 S6 在单子房系 77(2)中表达。

2.2 特异表达蛋白的二级质谱分析

基于串联质谱搜索数据库时, 搜索匹配主要是根据 谱图中离子峰的质荷比换算成分子质量后, 与数据库中
模拟的肽段离子或者碎片离子进行质量比较, 从而确定 是否能够匹配, Mascot 软件会根据匹配结果计算出一个分 值即离子得分, 代表这张谱图和这个肽段的匹配程度, 由 于一张谱图可能匹配上多个肽段, 因此会对应多个离子 得分, Mascot 软件根据这些分数分布计算出一个鉴定阈值, 使这个國值的期望值为默认的 0.05 。本实验鉴定得到的蛋 白质肽段匹配得分均远远高于鉴定阈值(表 1), 说明鉴定 结果可靠。

\section{3 讨论}

本实验供试材料为通过轮回选育创建的小麦多子房 近等基因系, 经过多年的田间观察和数据统计, 各回交世 代多子房性状均能稳定遗传。马守才等 ${ }^{[16]}$ 通过 APAGE 技 术对多子房近等基因系醇溶蛋白的研究表明, 4 代回交选 育的 77(2)多子房性状近等基因系与轮回亲本遗传相似性 达到 0.96 以上, 并经 SSR 分子标记对回交 5 代的多子房 近等基因系进行遗传背景检测, 也得到相似结果, 这使它 成为研究多子房相关基因和蛋白质组的理想材料, 通过 2-DE 获得的差异蛋白客观上与子房发育的调控直接相 关。如 SGT1-1(S2)、HMG-I/Y(S3)、果糖 1,6-二磷酸醛缩 酶(S5)在 Mu77(2)中特异表达而在 77(2)中缺失; 相反, 富 含甘氨酸 RNA 结合蛋白 $(\mathrm{S} 1)$ 、谷胱甘肽转移酶(S4)和未知 蛋白(S6) 在 77(2)中表达而在 Mu77(2)中缺失。

$\mathrm{S} 1$ 被鉴定为富含甘氨酸 RNA 结合蛋白 $(\mathrm{GRP})$ 。植物 GRP 是存在于细胞壁上的一种重要结构蛋白。Kim 等 ${ }^{[17]}$ 研究认为 GRP 通过调节 mRNA 输出保卫细胞, 促使双子 叶植物增强耐寒性; 他们还发现水稻干种子中也有 GRP 家族成员的存在, 在低温胁迫下, 能促进种子萌发和幼苗

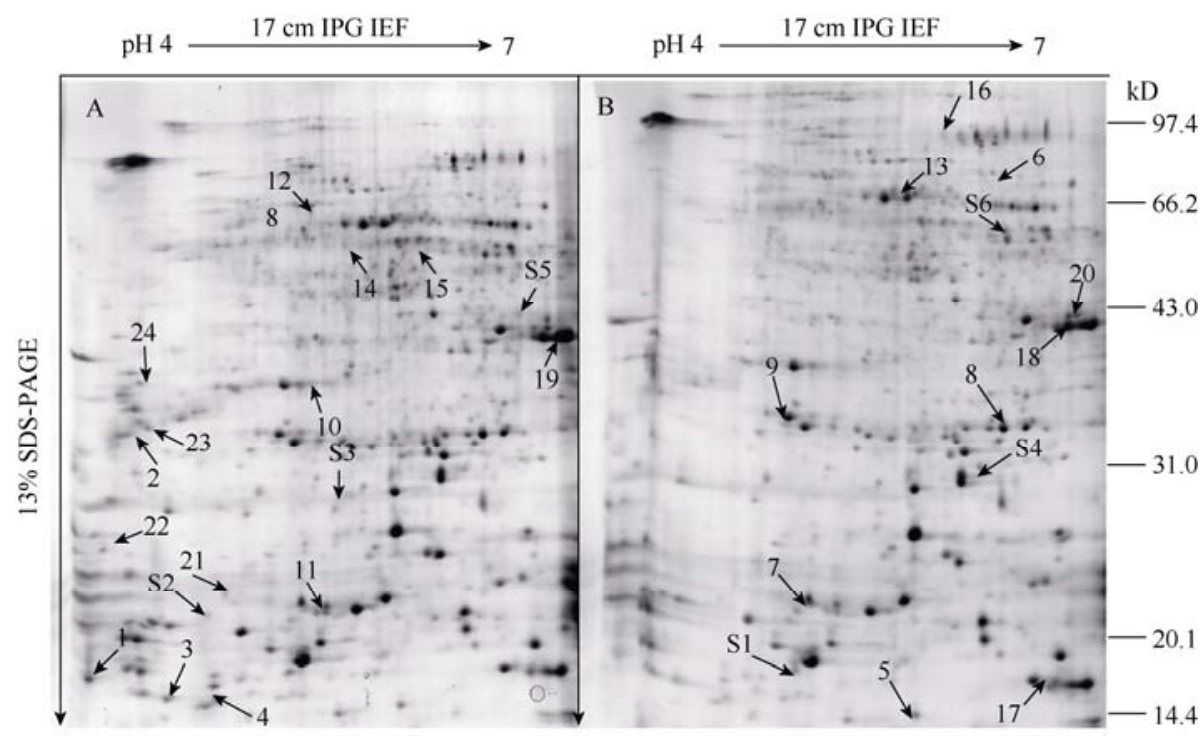

图 1 小麦多子房性状近等基因系和单子房性状系幼穗蛋白差异表达的双向电泳图谱

Fig. 1 Two-dimension electrophoretic maps of differential proteins isolated from young spikes between multi-ovary and mono-ovary wheat near isogenic lines

A：小麦多子房性状小麦 $\mathrm{Mu} 77(2)$; B：单子房小麦 77(2)。

A: Mu77(2) with multi-ovary trait; B: 77(2) with mono-ovary trait. 


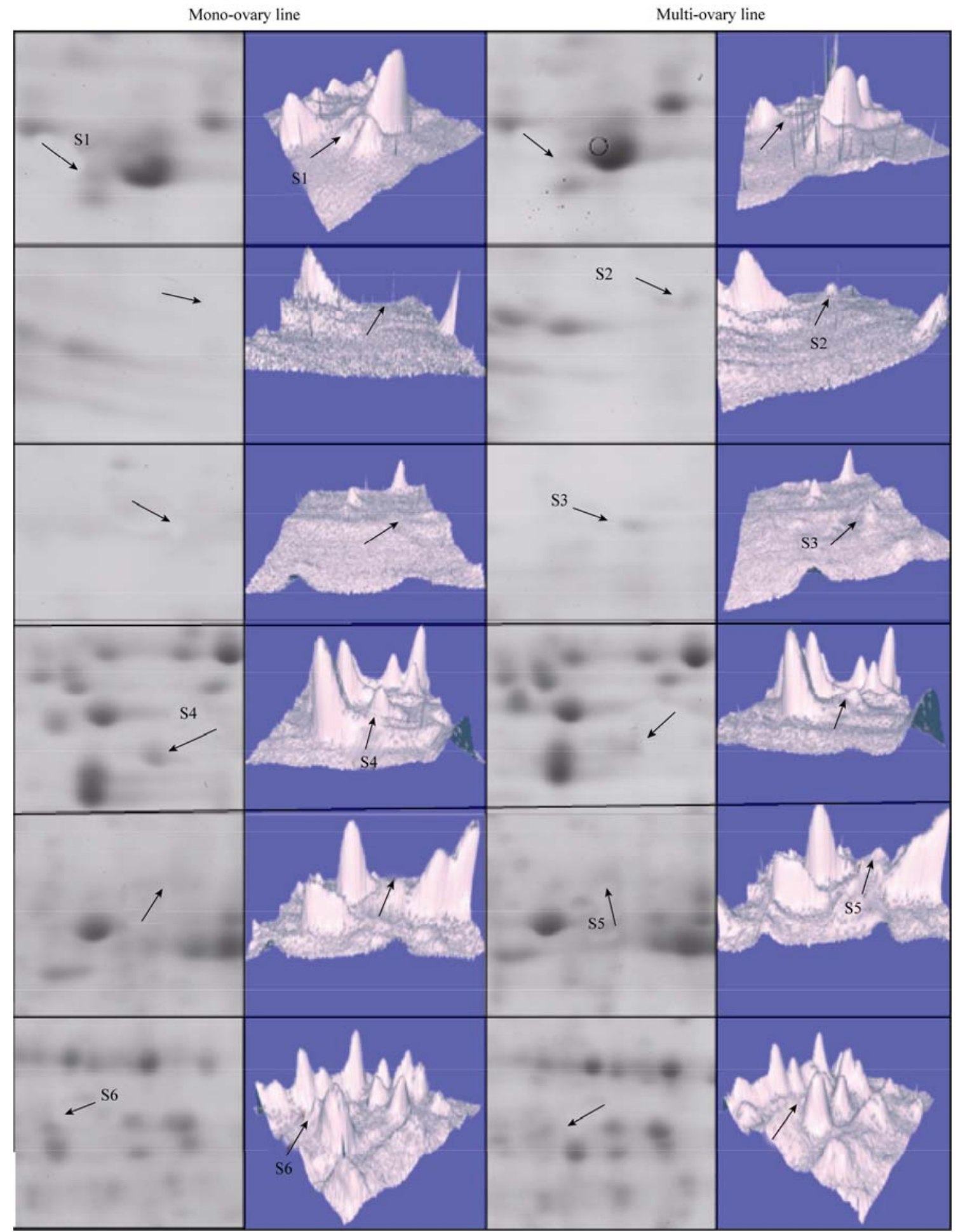

图 26 个特异蛋白点的三维模式图

Fig. 2 Three-dimension views of six specific-expression protein spots

2-DE 的局部放大图与对应的三维模式图进行对比, 差异蛋白序号同图 1 箭头示差异蛋白点位置, 单子房和多子房材料的箭头方向一致。 The 2-DE map and 3-D sketch map of the same protein spot are juxtaposed for comparison. The arrows show the differential protein spots, which are numbered as in Fig. 1. The arrows show the same spot position in mono-ovary or multi-ovary line are in identical direction.

生长; 通过 GRP 家族成员在水稻和拟南芥等植物适应逆 境胁迫的分子生物学方面的探索, 发现 GRP 参与基因转 录后调控, 其中包括质核 mRNA 转运、稳定性以及蛋白
质翻译等调节。Nomata 等 ${ }^{[18]}$ 对小立碗蘚(Physcomitrella patens)中 3 个 GRP 蛋白基因的研究发现, 这 3 个 GRP 的 转录和蛋白在冷处理后表达量都上调。卢秀萍等 ${ }^{[19]}$ 也认 
表 1 差异蛋白二级质谱鉴定结果

Table 1 Results of differentially expressed proteins identified by LC-MS/MS

\begin{tabular}{cccccccc}
\hline \multirow{2}{*}{$\begin{array}{c}\text { 编号 } \\
\text { Spot No. }\end{array}$} & $\begin{array}{c}\text { 登录号 } \\
\text { Accession No. }\end{array}$ & $\begin{array}{c}\text { 理论值 } \\
\text { Theoretical }\end{array}$ & $\begin{array}{c}\text { 实验值 } \\
\text { Experimental }\end{array}$ & $\begin{array}{c}\text { 分值 } \\
\text { Mascot } \\
\text { score }\end{array}$ & $\begin{array}{c}\text { 1) } \\
\text { sci覆盖率 } \\
\text { Sequence } \\
\text { Coverage } \\
(\%)\end{array}$ & $\begin{array}{c}\text { 鉴定肽段数/谱图数 } \\
\text { Peptide/spectrum }\end{array}$ & $\begin{array}{c}\text { 匹配蛋白 } \\
\text { Protein name }\end{array}$ \\
\hline S1 & gi|114145394 & $17.70 / 5.44$ & $16.04 / 6.70$ & 87.78 & 59.5 & $10 / 71$ & $\begin{array}{c}\text { Glycine-richRNA-binding } \\
\text { protein }\end{array}$ \\
S2 & gi|12654445 & $22.58 / 5.02$ & $41.41 / 4.70$ & 93.13 & 10.3 & $3 / 5$ & SGT1-1 \\
S3 & gi|20502966 & $36.06 / 4.58$ & $19.31 / 11.14$ & 33.66 & 44.4 & $8 / 21$ & HMG-I/Y protein HMGa \\
S4 & gi|23504745 & $30.86 / 5.01$ & $23.42 / 6.15$ & 59.76 & 48.8 & $8 / 137$ & Glutathione transferase \\
S5 & gi|226316441 & $43.02 / 6.03$ & $39.17 / 7.27$ & 76.47 & 25.4 & $12 / 62$ & Fructose-bisphosphate aldolase \\
S6 & gi|296525622 & $65.37 / 6.41$ & $48.12 / 5.70$ & 64.64 & 50.0 & $23 / 69$ & Unnamed protein \\
\hline
\end{tabular}

1)谱图的离子得分与该谱图鉴定阈值的差值。 ${ }^{1)}$ The protein matches score of irons score minus identity score.

为 GRP 的生物学功能可能涉及烟草抗逆性形成、逆境调 控和诱导 MicroRNA 小分子形成。本研究中, GRP 在 77(2) 中表达而在 Mu77(2)中缺失或表达量下调。此蛋白参与基 因转录后调控, 转录后调控和转录调控在基因表达调控 中起着同样重要的作用, 其调控决定基因表达最终产物 的种类和数量。多子房小麦缺乏该蛋白, 可能影响 mRNA 前体的加工, 或者发生剪接方式改变, 表达出特异蛋白质, 最终产生多子房性状, 这与田间观察的 Mu77(2)表现多子 房性状，而 77(2)表现单子房性状的现象一致。

S2 被鉴定为 SGT1 蛋白。最早在酵母中发现 SGT1, 由与发育相关的重要基因所编码。植物 SGT1 蛋白具有 5 个结构域，包括位于 N 端重复结构 TPR (tetratrico peptide repeat)、可变区 VR1 (variable region 1)和 VR2 (variable region 2)、CS (CHORD and SGT1)区和位于 C 端 SGS (SGT1special)区 ${ }^{[20]}$, 其中 TPR、CS 和 SGS 区对于 SGT1 蛋白功 能发挥至关重要。SGT1 蛋白以多种方式参与调控植物抗 病反应, 如调节 $R$ (抗病基因)蛋白复合体的积累水平 ${ }^{[21]}$, 调控植物的病原侵染点的超敏反应, 还与非宿主抗性密 切相关 ${ }^{[22]}$ 。王凯等 ${ }^{[23]}$ 认为 SGT1 的超量表达可以提高小 麦对黄矮病、白粉病的抗性。陈炜等 ${ }^{[4]}$ 研究表明, 多子房 小麦种胚萌发初期比单子房小麦种胚抗逆性增强。SGT1 可以和不同的蛋白, 如 SGT1、RAR1 和 HSP90, 通过互作 来实现分子伴侣功能; SGT1 也可能与 RAR1、SCF 和 COP9 信号体的 CSN 之间形成多种复合体, 这些复合体与 植物的泛素化相关, 进而通过泛素化来调节信号传递。本 实验室利用 SSH 技术构建了多子房和单子房相关基因特 异表达的抑制消减杂交 $\mathrm{cDNA}$ 文库, 发现 SGT1 基因在多 子房文库中出现 ${ }^{[10]}$, 进一步验证 SGT1 可能参与小麦多子 房性状的形成发育过程。

S3 被鉴定为 HMG-I 和 $\mathrm{Y}$, 现已改名为 HMGA，是染 色质蛋白, 与 DNA 结合会导致 DNA 弯曲、拉伸、成环或 解链, 因此也被称为“构架转录因子”(architectural transcription factor) ${ }^{[24]}$ 。 HMGA 作为转录因子的辅因子, 主要 通过使 DNA 分子变形参与增强体形成来调节真核生物基 因转录的起始。HMGA 的磷酸化可以引起细胞内蛋白质
的稳定性及其与 DNA 结合的波动, 从而精确地调控其调 节功能, HMGA 的甲基化与细胞的程序化死亡有密切关 系 ${ }^{[25]}$ 。此外, HMGA 还参与细胞核中许多其他活动,如病 毒整合、RNA 加工、DNA 修复、染色质结构重组等 ${ }^{[26]}$ 。 此蛋白均在 Mu77(2)中特异表达, 可能参与 DNA 复制、 转录、修复等一系列调控过程, 从而导致 DNA 或 mRNA 结构信息的改变，引起多子房性状表达。

S4 是谷胱甘肽转移酶(GST)。在植物的初级代谢和二 级代谢、耐受胁迫和细胞信号转导过程中, GST 行使不同 的功能, 从而影响植物的生长发育。植物 GST 的主要功 能在于解除外界毒素以及内源有毒代谢物的侵害 ${ }^{[27]}$ 。Zettl 等 ${ }^{[28]}$ 研究表明, GST 是生长素和细胞分裂素的结合蛋白, GST 涉及类黄素在细胞内结合和稳定的调节，而不是催 化它们的谷胱甘肽化 ${ }^{[29]}$ 。GST 与解除醛类化合物及类毒 素的毒性有关 ${ }^{[30]}$, 有些 GST 在细胞的氧化还原稳态和调 节细胞程序衰老中起作用 ${ }^{[31-32]}$ 。GST 不仅是一类多功能 的细胞脱毒酶, 还具有典型的谷胱甘肽转移酶活性和谷 胱甘肽过氧化物酶(GPX)的活性 ${ }^{[28]}$ 。GST 也在酪氨酸(Tyr) 代谢中有催化异构化的作用。该酶在 77(2)中特异表达而 在 Mu77(2)中缺失, 可能后者由于缺乏该蛋白, 导致一些 GST 调节功能异常, 促使子房发育持续进行, 引起多子房 性状的表达。

$\mathrm{S} 5$ 被鉴定为果糖 1,6-二磷酸醛缩酶, 简称醛缩酶, 催化果糖 1,6-二磷酸可逆地裂解为 2 个丙糖、磷酸二差丙 酮(DHAP) 和 3-磷酸甘油醛(G-3-P), 其活性功能涉及卡尔 文(Calvin)循环、糖酵解过程、糖异生过程以及氧化磷酸 戊糖途径等代谢途径 ${ }^{[33]}$, 直接调节 $3 \mathrm{C}$ 和 $6 \mathrm{C}$ 碳水化合物 之间的转换, 对生命体代谢过程发挥重要的作用。果糖 1,6-二磷酸醛缩酶是糖酵解过程中的关键酶, 近年的转录 组学和蛋白质组学研究表明, 果糖 1,6-二磷酸醛缩酶的表 达量与某些激素刺激和逆境胁迫密切相关 ${ }^{[34]}$ 。该酶在所 有生物体中均有表达, 之所以在 Mu77(2)中表达有差异, 可能是在幼穗发育过程中, 特别是副雌鰠的分化和生长 期间，需要额外的能量供应，从而诱导该酶的大量合成， 以维持多子房性状发育的能量正常供应。 


\section{References}

[1] Chen J-S(陈济世), Zhang L-H(张岭华), Wu B-L(吴秉礼). The preliminary report on the discovery and selection of "Three wheat”. Acta Agron Sin (作物学报), 1983, 9(1): 69-72 (in Chinese with English abstract)

[2] Ma S-C(马守才), Zhang G-S(张改生), Liu H-W(刘宏伟), Wang $\mathrm{J}-\mathrm{W}$ (王军卫). Studies on the application of multi-ovary character to hybrid wheat. Acta Bot Boreali-Occident Sin (西北植物学报), 2002, 22(6): 1295-1299 (in Chinese with English abstract)

[3] Wang Y-Z(王耀芝), Ding H-B(丁惠宾), Jin Z-L(金芝兰). Initiation and development of flowers in a multi-pistil wheat. Acta Bot Boreali-Occident Sin (西北植物学报), 1989, 9(3): 131-135 (in Chinese with English abstract)

[4] Chen W(陈炜), Liu W-Y(刘维营), Lei Q(雷清), Ding H-B(丁惠 宾), Wang L-S(王仑山). Comparative study of peroxidase isozyme and proteins of trigrainand and common wheat in seedlings. Acta Agron Sin (作物学报), 1999, 25(5): 650-653 (in Chinese with English abstract)

[5] Wang J-W(王军卫), Zhang G-S(张改生), Liu H-W(刘宏伟), Song Y-Z(宋亚珍), Niu N(牛娜). Detection of A RAPD marker linked to dominant multi-ovary gene in wheat (Triticum aestivum). J Agric Biotechnol (农业生物技术学报), 2005, 13(5): 553-556 (in Chinese with English abstract)

[6] Zhang G-H(张国慧), Zhang G-S(张改生), Ge F-H(葛峰辉), Niu $\mathrm{N}$ (牛娜), Ma S-C(马守才), Pan D-L(潘栋梁), Wang K(汪奎). Study on factors influencing penetrance of multi-ovary in wheat. J Plant Genet Resour (植物遗传资源学报), 2008, 9(4): 528-530 (in Chinese with English abstract)

[7] Shen G-H(沈光华), Tong Y-Z(童一中), Shen G-Z(沈革志). Localization of the gene multi-ovary on chromosome and chromosome-arm of common wheat using monosomic and ditelosomic analysis. Acta Genet Sin (遗传学报), 1992, 19(6): 513-516 (in Chinese with English abstract)

[8] Wu J(武军), Li B-Q(李邦琴), Zhao J-X(赵继新). Genetic analysis of multi-ovary character of trigrain wheat. $J$ Northwest Agric Univ (西北农业大学学报), 2000, 28(6): 58-60 (in Chinese with English abstract)

[9] Ma S-C(马守才), Zhang G-S(张改生), Niu N(牛娜). Breeding of near-isogeniclines of multi-ovary character in wheat and their genetic background evaluation. J Nucl Agric Sci (核农学报), 2007, 21(6): 585-588 (in Chinese with English abstract)

[10] Li X F, Ma S C, Zhang G S, Niu N, Wei F, Rebonoang T, Zhao H. Identification and expression analysis of genes related to multi-ovary in wheat (Triticum aestivum L.). Seed Sci Technol, 2011, 20: 54-73

[11] Xu Y-P(徐幼平), Xu Q-F(徐秋芳), Cai X-Z(蔡新忠). Optimization of total protein extraction from tomato leaves for two-D gel electrophoresis analysis. Acta Agric Zhejiangensis (浙江农业学 报), 2007, 19(2): 71-74 (in Chinese with English abstract)
[12] Chen R-H(陈荵红), Ye J-X(叶景秀), Zhang G-S(张改生), Wang $\mathrm{J}-\mathrm{S}$ (王俊生), Niu N(牛娜), Ma S-C(马守才), Zhao J-X(赵继新), Zhu J-C(朱建楚). Differential proteomic analysis of anther proteins between cytoplasmic-nuclear male sterility line and its maintainer in wheat (Triticum aestivum L.). Prog Biochem Biophys (生物化学与生物物理进展)，2009，36(4)：431-440 (in Chinese with English abstract)

[13] Bradford M M. A rapid and sensitive method for the quantitation of microgram quantities utilizing the principle of protein dye binding. Anal Biochem, 1976, 72: 248-254

[14] Ye J-X(叶景秀), Chen R-H(陈芯红), Zhang G-S(张改生), Wang J-S(王俊生), Wang S-P(王书平), Li L(李莉), Niu N(牛娜), Ma S-C(马守才), Li H-X(李红霞), Zhu J-C(朱建楚). Analysis on anther proteins of wheat male sterile line induced by chemical hybridizing agent SQ-1. J Agric Biotechnol (农业生物技术学报), 2009, 17(5): 858-864 (in Chinese with English abstract)

[15] Wang J(汪静), Yuan L(袁琳), Chen X-M(陈晓明). An Improved technique for protein staining with CBB G250. J Med Mol Biol (医学分子生物学杂志), 2006, 3(6): 423-425 (in Chinese with English abstract)

[16] Ma S-C(马守才), Zhang G-S(张改生), Niu N(牛娜). Breeding of near-isogenic lines of multi-ovary character in wheat and their genetic background evaluation. J Nucl Agric Sci(核农学报), 2007, 21(6): 585-588 (in Chinese with English abstract)

[17] Kim J Y, Kim W Y, Kwak K J, Oh S H, Han Y S, Kang H S. Glycine-rich RNA-binding proteins are functionally conserved in Arabidopsis thaliana and Oryza sativa during cold adaptation process. J Exp Bot, 2010, 61: 2317-2325

[18] Nomata T, Kabeya Y, Sato N. Cloning and characterization of glycine-rich RNA-binding protein cDNAs in the moss Physcomitrella patens. Plant Cell Physiol, 2004, 45: 48-56

[19] Lu X-P(卢秀萍), Chen X-J(陈学军), Liu Y(刘勇), Tang Q-H(唐 启慧), Chen Y-B(陈禹保), Li W-Z(李文正). Expression of the glycine-rich RNA-binding protein of tobacco in E. coli . China Biotechnol (中国生物工程杂志), 2010, 30(8): 29-30 (in Chinese with English abstract)

[20] Azevedo C, Sadanandom A, Kitagawa K, Freialdenhoven A, Shirasu K, Schulze-Lefert P. The RAR1 interactor SGT1, an essential component of $R$ gene-triggered disease resistance. Science, 2002, 295: 2073-2076

[21] Holt III B F, Belkhadir Y, Dangl J L. Antagonistic control of disease resistance protein stability in the plant immune system. Science, 2005, 309: 929-932

[22] Zheng H-J(郑宏江), He S-J(何锶洁), Dai S-H(戴顺洪). Some improvements of the biolistic transformation system for Oryza. Chin J Biotechnol (生物工程学报), 1994, 12(suppl): 111-115 (in Chinese with English abstract)

[23] Wang K(王凯), Du L-P(杜丽璞), Zhang Z-Y(张增艳), Liao Y(廖勇), Xu H-J(徐惠君), Yao W-L(姚乌兰), Yang K(杨昆), Shao Y-J(绍艳军), Xin Z-Y(辛志勇). Isolation and preliminarily 
functional analysis of SGT1 gene of Thinopyrum intermedium. Acta Agron Sin (作物学报), 2008, 34(3): 520-525 (in Chinese with English abstract)

[24] Baxevanis A D, Landsmanb D. The AMG-1 box protein family: classification and functional relationships. Nucl Acids Res, 1995, 23: $1604-1613$

[25] Riccardo S, Salvina Z, Alessandra L S, Elisa M, Laura A, Silvia P, Vincenzo G, Guidalberto M. HMGA molecular network: from transcriptional regulation to chromatin remodeling. Biochim Biophys Acta, 2010, 1799: 37-47

[26] Martinez H J, Fedele M, Battista S. Identification of the genes up-and down-regulated by the high mobility group A1 (HMGA1) proteins: tissue specificity of the HMGA1-dependent gene regulation. Cancer Res, 2004, 64: 28-35

[27] Cai Q-F(蔡群芳). The research of glutathione $S$-transferase. $J$ Hainan Med Univ (海南医学院学报), 2011, 17(12): 1735-1737 (in Chinese with English abstract)

[28] Zettl R, Schell J, Palme K. Photoaffinity labeling of arabidopsis thaliana plasma membrane vesicles by 5 -azido- $\left[7-{ }^{3} \mathrm{H}\right]$ indole3-acetic acid: identification of a glutathione $S$-transferase. Proc Natl Acad Sci USA, 1994, 91: 689-693
[29] Edwards R, Dixon D P, Walbot V. Plant glutathione S-transferases: enzymes with multiple functions in sickness and in health. Trends Plant Sci, 2000, 5: 193-198

[30] Mitrovic S M, Pflugmacher S, James K J. Anatoxina elicits an increase in peroxidase and glutathione $S$-transferase activity in aquatic plants. Aquat Toxicol, 2004, 68: 185-192

[31] Roxas V P, Smith R K, Allen E R, Allen R D. Over expression of glutathione $S$-transferase/glutathione peroxidase enhances the growth of transgenic tobacco seedlings during stress. Nat Biotechnol, 1997, 15: 988-991

[32] Moons A. Regulatory and functional interactions of plant growth regulators and plant glutathione S-transferases (GSTs). Vitam Horm, 2005, 72: 155-202

[33] Penh O, Rajkumar T, Rutter W J. Multiple forms of fructose diphosphate aldolase in mammalian tissues. Proc Natl Acad Sci USA, 1966, 56: 1275-1282

[34] Wei F, Zhili Z, Yan L Z. Cloning and molecular characterization of fructose-1,6-bisphosphate aldolase gene regulated by high-salinity and drought in Sesuvium portulacastrum. Physiol Biochem, 2009, 28: 975-984 